\title{
An Antenna with Good Electrical Properties and Artistic Shape for Lampshade
}

\author{
Chang ZHOU, Yang YU, Chen JI \\ Wisdom Engineering, Wuhan Second Ship Design and Research Institute, Hubei 430074, China
}

\begin{abstract}
An improved transparent antenna based on transparent ceramic $\mathrm{MgAl}_{2} \mathrm{O}_{4}$ with artistic shape which can be used as lampshade is presented in this paper. A great peak gain and good pattern can be achieved by choosing the property shape and optimizing location of the feed of the antenna. Simulation results indicate that this antenna can achieve return loss $>-15 \mathrm{~dB}$, peak gain $>8 \mathrm{dBi}$ at $2 \mathrm{GHz}$ and $40 \%$ relative impedance bandwidth. Both the electrical properties and artistic shape of the antenna are realized and the lampshade which made by $\mathrm{MgAl}_{2} \mathrm{O}_{4}$ meets the requirement for communication, decoration and high light transmission.
\end{abstract}

\section{Introduction}

Recently, the modern wireless communication systems have been rapidly increased and more requirements such as special structure, small size and multi-function have been made [1]-[2]. The dielectric resonator antenna based on low loss dielectric materials has some pretty advanced features ranging from greater design flexibility, smaller size, lower loss, wide impedance bandwidth which is suitable for the design of antenna with special size and good electrical properties [3]-[7]. On the other side, new types of dielectric material have been improved and applied and the antennas based on dielectric material can have more features. Among various types of materials, the transparent ceramics with the advantages of high light transmittance, low loss and good mechanical properties has a certain development in lighting,

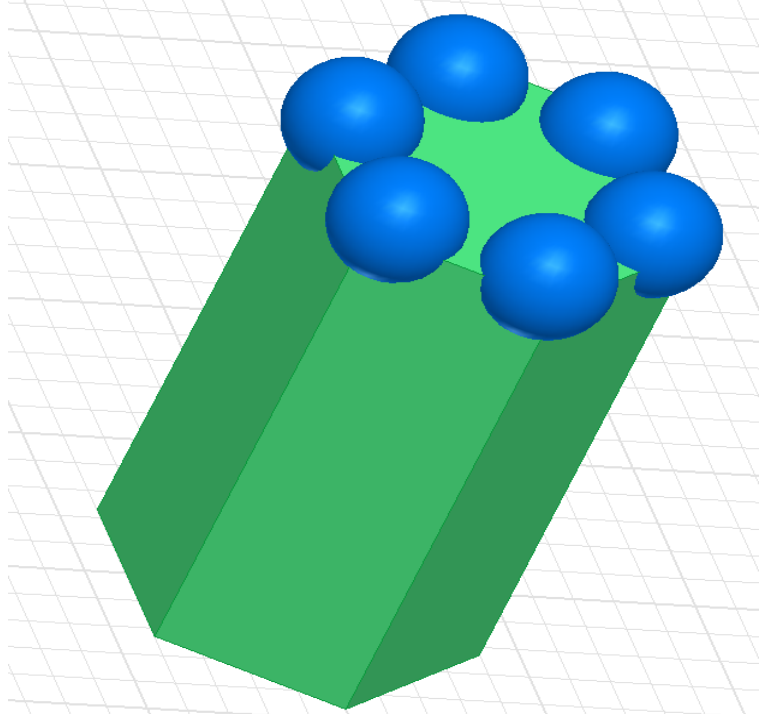

(a) temperature insulation and so on [8]-[10]. The antenna based on transparent ceramics with special function can be made.

In this paper, we present the method to design lampshade with multi-function by using transparent ceramic. A type of transparent ceramic with low loss and high light transmittance were chosen and the influence of the shape and feed on the electrical properties of the antenna were analyzed.

\section{Models with Artistic Shape}

The electrical properties of the transparent ceramics $\mathrm{MgAl} 2 \mathrm{O} 4$ is: permmitivity $(\varepsilon r)=8.38, \mathrm{Qf}=57000 \mathrm{GHz}$, the temperature coefficient of dielectric constant $\mathrm{tf}=-76 \mathrm{ppm} /{ }^{\circ} \mathrm{C}$, light transmittance $=70 \%$ and the structure of the antenna is chosen as shown in Figure 1 which ensures the artistic shape.

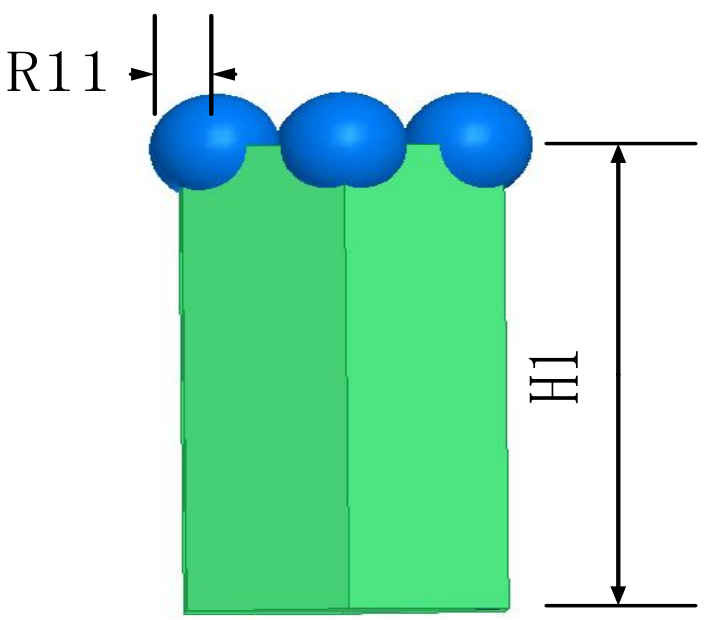

\footnotetext{
* Corresponding author: rabbite6@126.com
} 


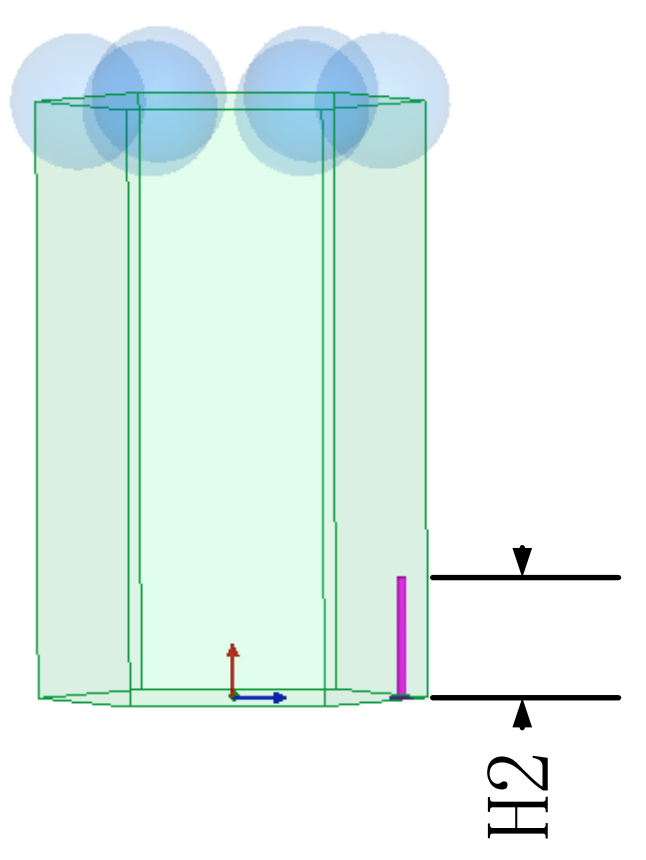

(c)

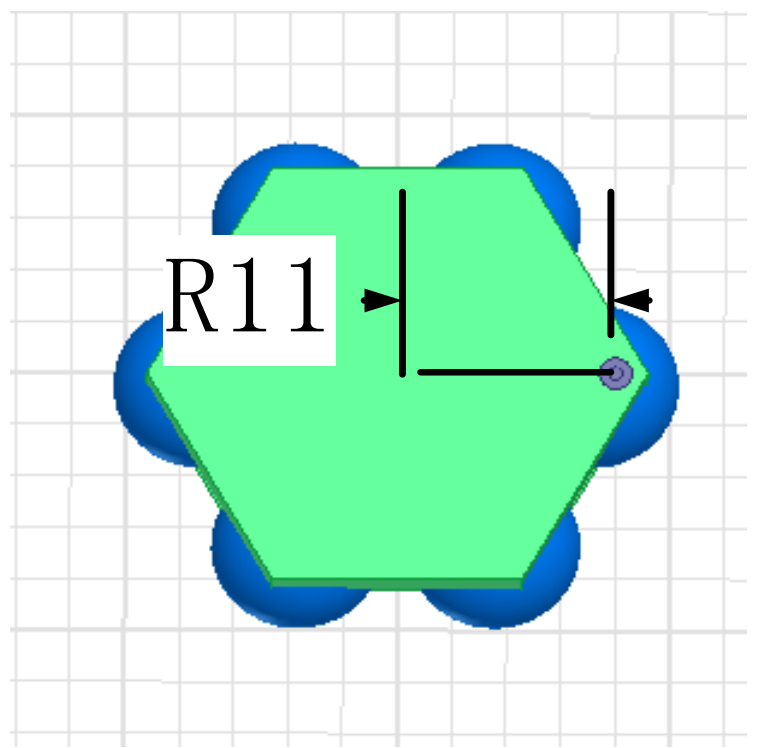

(d)

Figure 1 The shape chosen from iron gate

It can be seen that the antenna is made of regular hexagonal prism and six ball which ensures the artistic shape of the lampshade. On the other side, the target electrical properties of the antenna is fo $=2 \mathrm{GHz}$, relative impedance bandwidth $>80 \%$, return loss $>-20 \mathrm{~dB}$ and peak gain $>8 \mathrm{dBi}$, respectively.

Here: the height of the ball is $\mathrm{H} 1$, the radius of the ball is R11, the distance of the ball from the center of the regular hexagonal prism is $23 \mathrm{~mm}$, the length of the side of the regular hexagonal prism is $23 \mathrm{~mm}$, the height of the regular hexagonal prism is $\mathrm{H} 1$, the height of the feed is $\mathrm{H} 2$ and the distance from the feed to the center of the regular hexagonal prism is $\mathrm{R} 12$, respectively.

\section{Simulation Examples}

For the artistic shape of the lampshade, some parameters of the structure is fixed such as the length of the side of the regular hexagonal prism. On the other side, the values of H1, H2, R11 and R12 are optimized to obtain the electrical properties and the simulation results are shown in Table 1.

Table 1 The simulation results of the antenna based on transparent ceramics

\begin{tabular}{|c|c|c|c|c|c|c|c|c|}
\hline Number & $\mathrm{H} 1[\mathrm{~mm}]$ & $\mathrm{H} 2[\mathrm{~mm}]$ & $\mathrm{R} 11$ [mm] & $\mathrm{R} 12[\mathrm{~mm}]$ & $\begin{array}{c}\text { Fo } \\
{[\mathrm{GHz}]}\end{array}$ & $\begin{array}{c}\text { Return } \\
\text { Loss }[\mathrm{dB}]\end{array}$ & $\begin{array}{c}\text { Grain } \\
\text { Peak }[\mathrm{dB}]\end{array}$ & $\begin{array}{c}\text { Ralative } \\
\text { Bandwidth }\end{array}$ \\
\hline 1 & 70 & 14 & 8 & 20 & 1.898 & -9.7 & 7.0 & - \\
\hline 2 & 70 & 14 & 8 & 15 & 1.898 & -11.3 & 6.6 & $4 \%$ \\
\hline 3 & 70 & 14 & 8 & 10 & 1.898 & $-8,3$ & 8.9 & - \\
\hline 4 & 70 & 18 & 8 & 15 & 2.0 & -21.3 & 7.8 & $85 \%$ \\
\hline 5 & 80 & 18 & 8 & 15 & 2.0 & -22.6 & 8.2 & $90 \%$ \\
\hline 6 & 80 & 18 & 5 & 15 & 2.0 & -21.6 & 8.8 & $92 \%$ \\
\hline
\end{tabular}

The simulated return-loss results and the radiation patterns at $2 \mathrm{GHz}$ are shown in Figure 2 and Figure 3. 


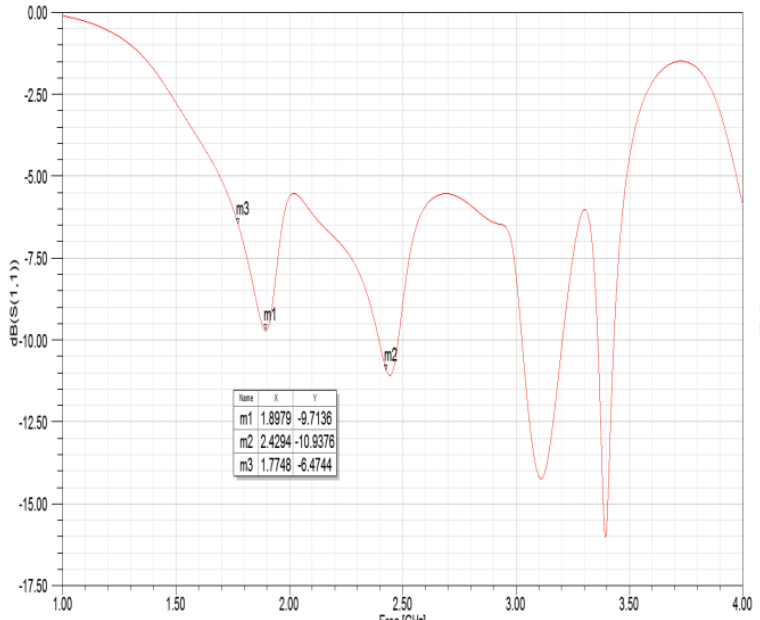

(a)

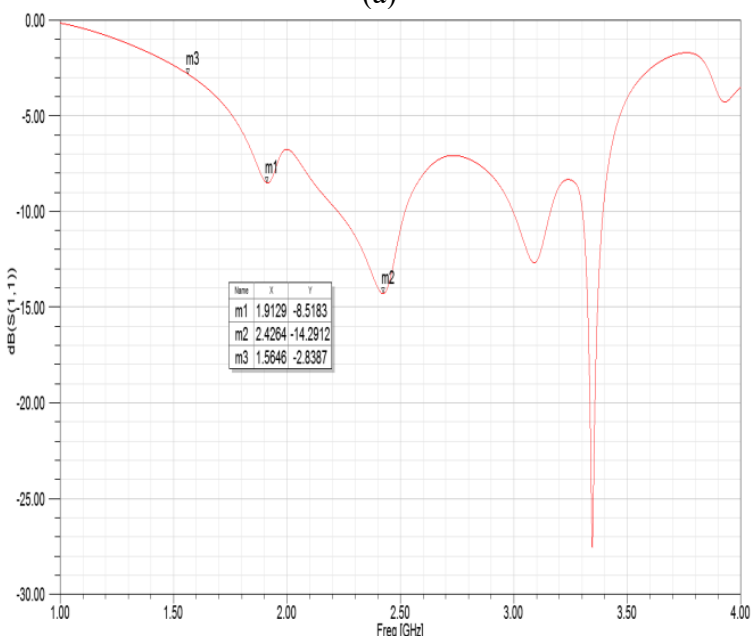

(c)

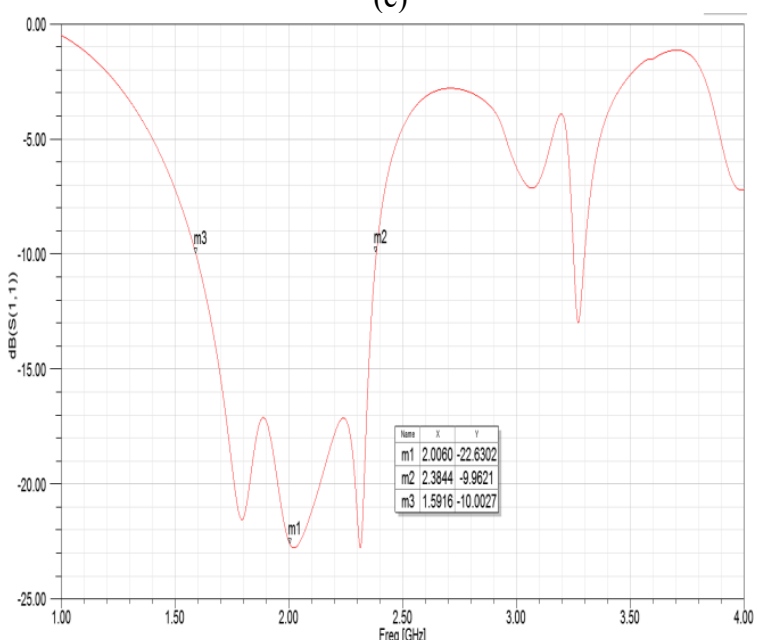

(e)

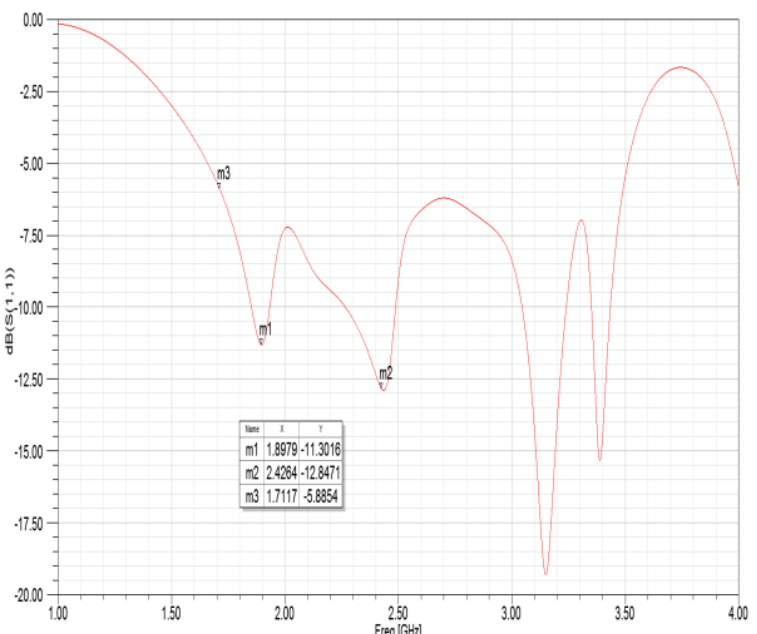

(b)

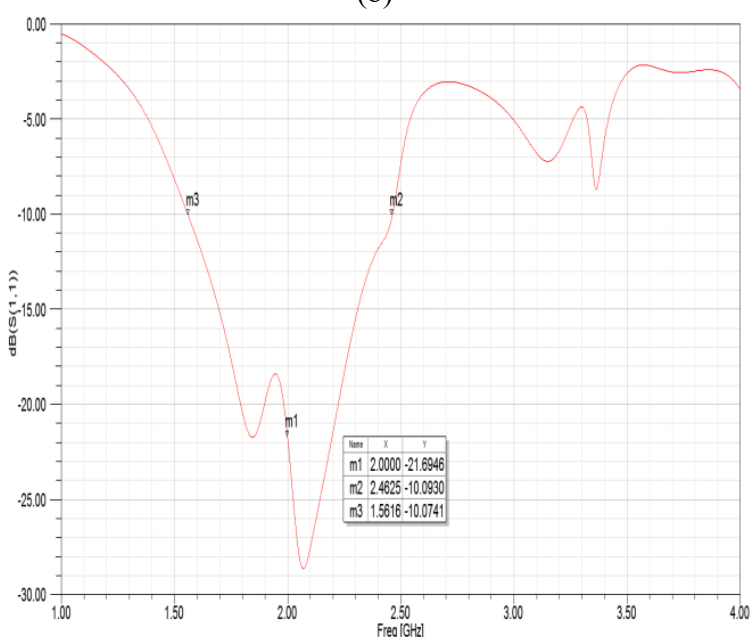

(d)

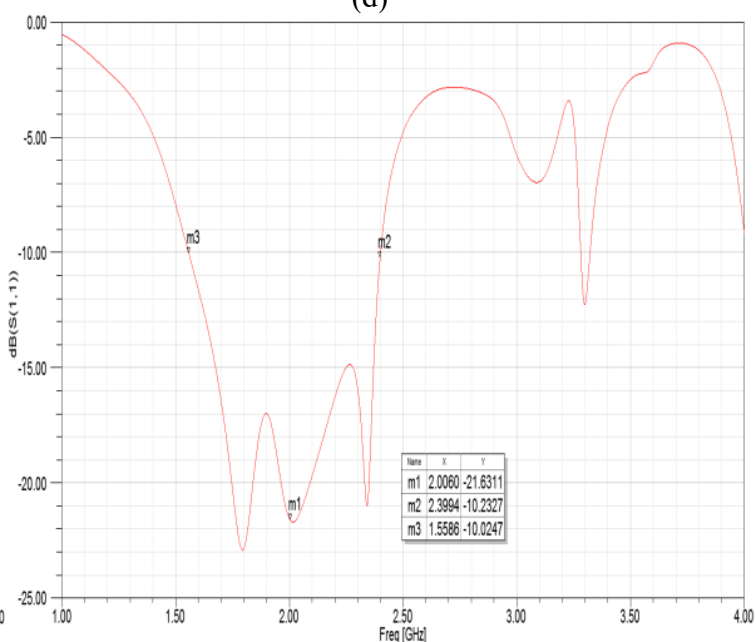

(f)

Fig. 2 The return loss of the antennas based on transparent ceramic

It could be seen that, by choosing proper material and parameter of the antenna, center frequency of the antenna could be controlled.

\section{3.}




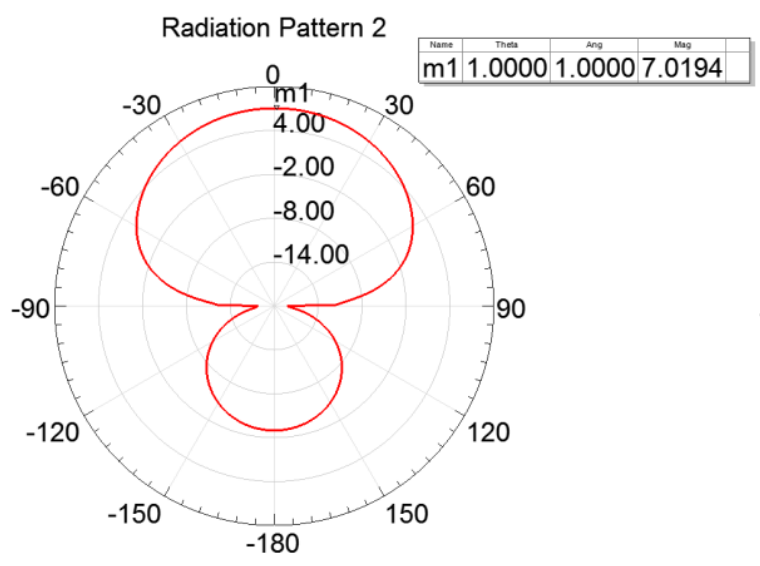

(a)

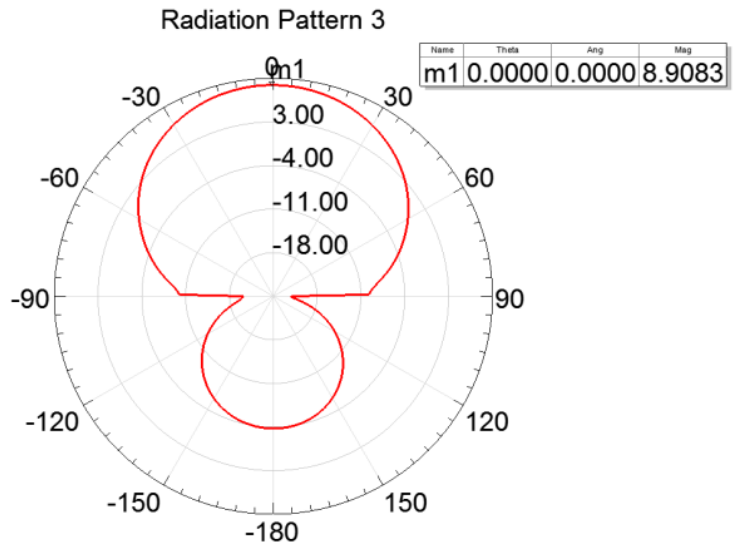

(c)

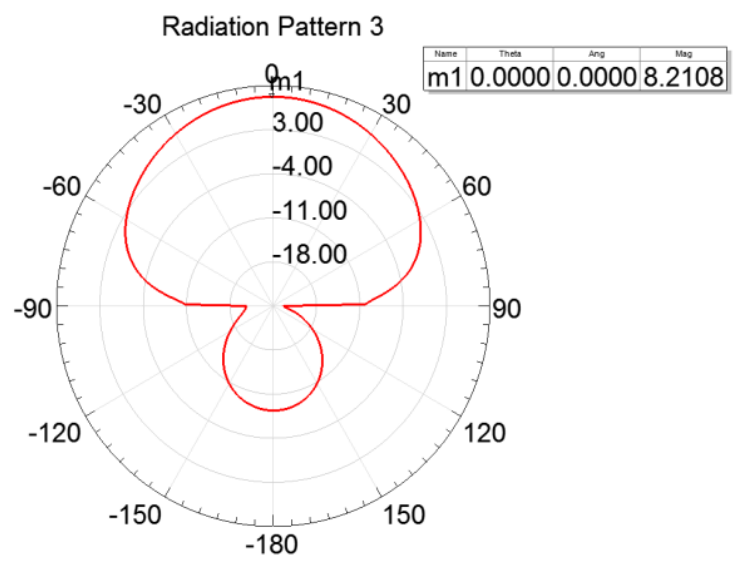

(e)
It was found that the sturcture is important for some key paramters and the satisfactory results can be obtained. As shown in Figure 2 and Figure 3, the relative impedance bandwidth of the transparent antenna are especially affected by adjusting the height of the coaxial feed and the center frequency of the antenna can be controlled by varying the height of the regular hexagonal prism. On the other side the distance of the feed from the center of the regular hexagonal prism and the radius of the ball have a less important influence on the electrical properties of the antenna.

The best combination of microwave parameters for the antenna based on transparent ceramic is got at $\mathrm{H} 1=80 \mathrm{~mm}, \mathrm{H} 2=18 \mathrm{~mm}$ and $\mathrm{R} 11=5 \mathrm{~mm}, \mathrm{R} 12=15 \mathrm{~mm}$,

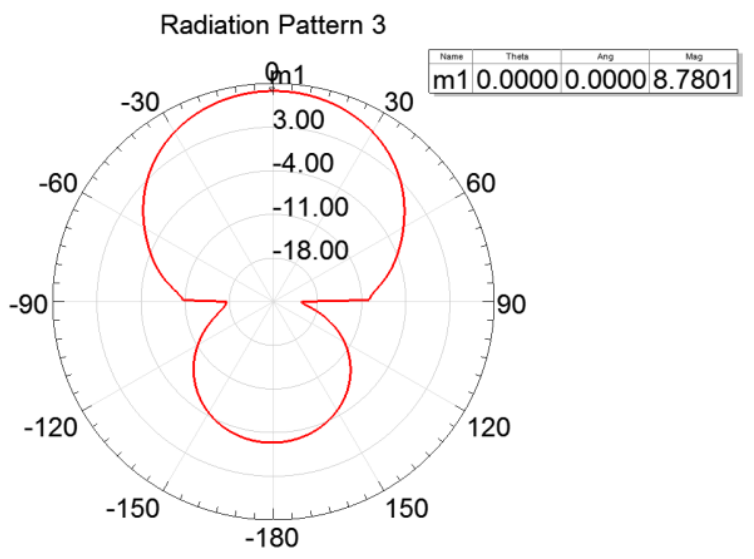

(f)

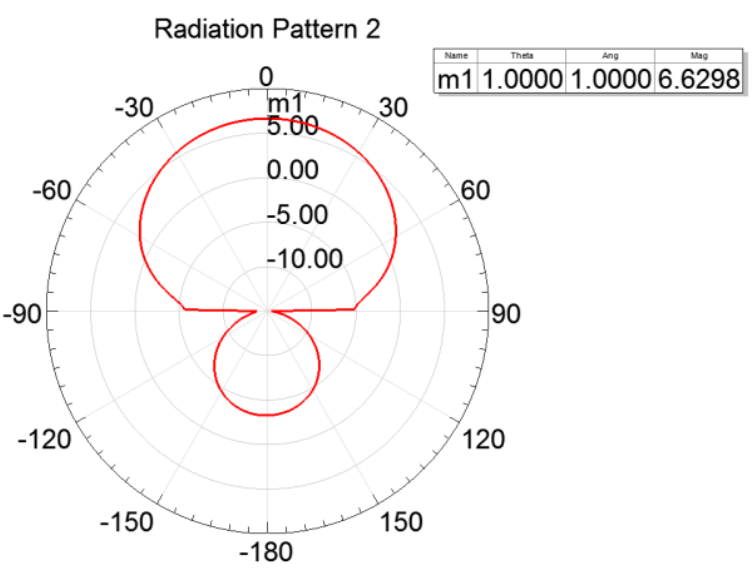

(b)

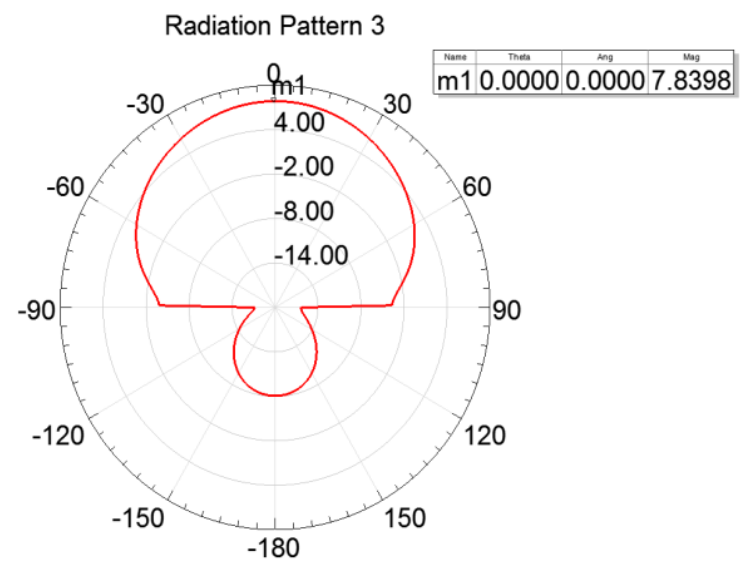

(d)

antennas based on transparent ceramic which yields properties of: fo $=2.0 \mathrm{GHz}$, return loss $=-21.6 \mathrm{~dB}$, peak gain $=8.8 \mathrm{~dB}$ and the relative bandwidth $=92 \%$.

\section{Conclusion}

This paper give a method to fabricate an antenna based on transparent ceramic. The antenna with good electrical properties, artistic shape and high light transmission was designed and the affection of the shape and location of tap of the antenna were summarized and presented. On the other side, it can be concluded that the lampshade and antenna can be integrated by choosing property material 
and structure. This method will be useful for the design of beautiful lampshade which also can be used as antenna for communication.

\section{References}

1. [1] Li Y F, Kwork W L. Dual-Fed Hollow Dielectric Antenna for Dual-Frequency Operation With Large Frequency Ratio[J]. IEEE Transactions on Antennas and Propagation, 2017, 65(6): 3308-3313.

2. Yang C, Zuping Q, Yingsong Z. A Compact Wideband SIW-Fed Dielectric Antenna With End-Fire Radiation Pattern[J]. IEEE Transactions on Antennas and Propagation, 2016, 64(4): 1502-1507.

3. Payam N, Min L, Rafael A S. A 3D Printed Dielectric Reflectarrays: Low-Cost High-Gain Antennas at Sub-Millimeter Waves[J]. IEEE Antennas and Propagation Society, 2014, 62(4): 2000-2008.

4. Nasser G, Ke W. Planar Dielectric Rod Antenna for Gigabyte Chip-to-Chip Communication[J]. IEEE Transactions on Antennas and Propagation, 2012, 60(10): 4924-4928.

5. Yonghun C, Jungyub L, Joonghee L. Quad-Band Monopole Antenna Including LTE $700 \mathrm{MHz}$ With Magneto-Dielectric Material[J]. IEEE Transactions on Antennas and Propagation, 2012, 11: 137-140.

6. J B Birks. Dielectric housings for centimetre-wave antennae. Part 2: Design practice for airborne radar

[J]. Journal of the Institution of Electrical Engineers Part IIIA: Radiolocation, 1946, 93(4): 653-657.

7. G M Whitman, C Pinthong, A A Triolo. An approximate but accurate analysis of the dielectric wedge antenna fed by a slab waveguide using the local mode theory and Schelkunoff equivalence principle[J]. IEEE Transactions on Antennas and Propagation, 2006, 54(4): 1111-1121.

8. Jian X, Lingcong F, Ying S. Scintillation and Luminescent Properties of Cerium Doped Lutetium Aluminum Garnet (Ce:LuAG) Powders and Transparent Ceramics[J]. IEEE Nuclear and Plasma Sciences Society, 2014, 61(1): 373-379.

9. Yun T W, Lai S Q, Hong S S. Preparation of Europium-Doped Gadolinium Lutetium Oxide Solid Solution Transparent Ceramics and Its Optical Properties[J]. IEEE Nuclear and Plasma Sciences Society, 2010, 57(3):1343-1347.

10. Yu S, Yong B, Nan Z. Experimental and Theoretical Investigation of Pump Laser Induced Thermal Damage for Polycrystalline Ceramic and Crystal Nd:YAG[J]. IEEE Journal of Selected Topics in Quantum Electronics, 2015, 21(1):4924-4928. 